\title{
UNA SÍNTESIS NEOCONSERVADORA DE LA HISTORIA DE AMERICA LATINA UNA CRÍTICA HISTORIOGRÁFICA Y POLÍTICA
}

\section{A propósito de L'Amerique latine. De l'Independance a nous jours, De François Che valier .}

\section{Renan Vega Cantor ${ }^{1}$}

Introducción: François Chevalier es uno de los latinoamericanistas franceses de más renombre. Es conocido desde la década del 50 por su trabajo sobre la formación de los grandes latifundios en México y posteriormente por investigaciones más puntuales sobre diversos aspectos de la historia de México y de otros países del continente. Teniendo en cuenta esta trayectoria, era de esperarse una actualización de la síntesis histórica del continente que este autor había publicado originalmente en 1977. En efecto, una nueva versión de La Historia de la América Latina de la Independencia a Nuestros Días fue publicada en 1993. En este grueso volumen de 725 páginas se intentan aplicar a la his toria latinoamericana las diversas tendencias de la llamada Nouvelle Histoire française, amalgamándolas con las diversas etapas de l' historia de los Anales.

En este ensayo vamos a hacer una crítica his toriográfica y política de este libro. De una parte, intentamos rastrearsus límites teóricos y metodológicos, y, de otra, planteamos una crítica política del texto en aquellos temas en que claramente se vis lumbra una postura neoconservadora para interpretar la historia contem poránea del continente.

Para la elaboración de este ensayo hemos partido de la siempre actual sugerencia de Goethe, para quien "en el tiempo presente nadie debe permanecer en silencio o renunciar. Ha de hablarse claro y actuar. No con el fin de triunfar sino de permanecer en nuestro puesto, sea con la mayoría o con la minoría, eso es lo mismo. Se debe repetir aquello que uno cree, proclamar aquello con lo que se está de acuerdo y citar aquello que uno condena....Gris, querido amigo, es la teoría y verde es el dorado árbol de la vida". Estos presupuestos nos han guiado a la hora de escribir esta crítica.

\section{Balbuceos metodológicos}

Al comienzo del libro, François Chevalier señala los criterios básicos a partir de los cuales ha elaborado la síntesis de la historia latinoamericana. Los

\footnotetext{
*. François Chevalier, (avec la colaboration de Yves Saint-Geours), L'Amérique latine. De l'Indépendance á nous jours, Presses Universitaires de France. Collection Nouvelle Clio, l'histoire et ses problemes, 2a édition refondue, Paris, 1993, $725 \mathrm{p}$.

${ }^{I}$ Profesor Universidad Pedagógica Nacional. DEA en Historia de América Latina, Universidad de París
} 
señalaremos, pero enunciaremos también nuestras reservas, en concordancia con nuestra lectura:

a. "Aprovechar la experiencia personal del autor, teniendo en cuenta la larga duración, en las investigaciones de Archivos, principalmente de México". ( $p, X \mathrm{X})$. De entrada este es un problema y no una ventaja, como podría parecer a primera vista, pues to que, en la medida de lo posible, en proceso de síntes is un historiador debe procurar desligarse de sus objetos de estudio particulares y de la documentación primaria. Si no lo hace puede reproducir o ocuparse en exceso de los resultados de sus investigaciones específicas, sin ver el panorama general. Esto fue lo que le sucedió a Chevalier con el caso de la historia de México, que prácticamente sustituye a la historia de América Latina.

b. "Considerar la observación del presente teniendo en cuenta las continuidades y rupturas con el pasado, una especie de historia regresiva, según las palabras de Marc Bloch" (p. XI). Este es un presupuesto más retórico que real, pues en el libro no se observa por ninguna parte la aplicación de tal método. Lo que hay es únicamente un arbitrario desplazamiento temporal en todos los capítulos, de la colonia, a la independencia, al siglo XIX y, marginalmente al siglo XX. Si en algún momento el "método regresivo" se ha aplicado en el libro solo ha sido para justificar la adopción del neoliberalismo en América Latina, o para ratificar su interpretación neoconservadora de otros hechos, tales como la Teología de la Liberación, la Revolución Cubana, el modelo mexicano de Salinas de Gortari, etc.

c. "La utilización del método comparativo, a partir de los estudios más notables sobre un problema o un país, tal es el caso de la historia política de México, estudiada por F. Guerra y con la cual se puede ayudar a comprender la historia de otros territorios" (X). Una cosa es emplear el método comparativo y otra cosa es concentrarse desmedidamente en un país, en el caso de este libro en México, salpicándolo por momentos con uno que otro elemento de la historia de los otros países. Como veremos el autor teminó escribiendo no una historia comparativa de América Latina sino una historia comparada de México.

d. Presentar la historia, "por grandes temas... económicos, sociales, culturales, conceptualizados en la larga duración" para "restituir en todos los dominios el acontecimiento, que se mantiene como el hito indis pensable de la historia" (p. XII). Cuando esto es hecho sin ningún eje explicativo central, se terminan proponiendo un conjunto deshilvanado de sucesos. A eso conduce el abandono de la totalidad, para abordar todas las partes por separado, sin que sea claro, ni desde el punto de vista espacial ni temporal, cuáles son los nexos existentes entre las diversas esferas estudiadas. El resultado es evidente en Chevalier, un texto absolutamente caótico, desordenado y sin un hilo conductor definido. Como veremos, en estas premisas ya están contenidas muchas de las debilidades del libro. 


\section{Una cronología "inocente"}

Antes de comenzar la exposición propiamente dicha, en el libro se presentan una serie de elementos introductorios excesivamente largos y poco justificados en un trabajo de síntesis. Nos referimos a la cronología y a la bibliografía, que ocupan el 20 por ciento del texto, lo que de por si lo alarga innecesariamente. Tanto la bibliografía como la cronología podían haber sido presentados en un libro aparte para uso de los historiadores profesionales interesados en América Latina, pues es seguro que ni a los estudiantes ni al lector convencional eso les interesa.

El listado bibliográfico ocupa el 10 por ciento de todo el libro (p. 1 a 77). Es una enumeración de las fuentes y documentos de base, guías bibliográficas y obras generales sobre cada país. La cronología del período 1804-1993 (p. 81-139), incluye: la península ibérica, los Estados Unidos y el mundo; México, América Central y el Caribe; y, América del Sur. Hay, igualmente, algunas informaciones estadísticas sobre la evolución económica, demográfica y productiva de América Latina. Ya en la cronología se encuentran problemas de interpretación, política y analíticamente bastante discutibles, que permiten ver las intenciones del autor. Citemos solo algunos ejemplos relacionados con la historia del siglo XX:

"1922-1933: Resistencia de Sandino con guerrilleros latinoamericanos, muerto (sic) en 1934 (s.p.).

1951-1954: Guatemala: Coronel Arbenz presidente electo, reforma agraria, influencias marxistas. Des tituido (sic) con el apoyo de Estados Unidos".

1958: Nicaragua: Somoza asesinado.

1967: Bolivia: muerte (sic) del Che Guevara.

1973: Sublevamiento (sic) militar, muerte de Allende.

1983: La isla de Grenada es ocupada por los Estados Unidos 'contra la subversión soviético-cubana'”.

El lenguaje que se emplea en la presentación de estos hechos o es falso o es la reproducción de un discurso conservador y pronorteamericano sobre la his toria del continente. Sabemos que el lenguaje que se em plea en un discurso, cada palabra, cada matiz contiene una carga valorativa, una apreciación o un punto de vista. Desde luego, la opción política escogida por Chevalier se aprecia claramente des de el comienzo del libro. En cuanto a estos datos, escogidos entre muchos, no deja de ser sorprendente que se diga alegremente que mientras Sandino, el Che o Allende fueron muertos, Somoza si fue asesinado. Es decir que aquellas personas de izquierda, marxistas, o que se han opuesto a la dominación norteamericana, pueden considerarse como muertos no importan la circunstancias bajo las cuales en realidad fueron asesinados. El cobarde as esinato de Sandino por parte de los esbirros de Somoza a comienzos de $1934^{2}$, o el del Che en

\footnotetext{
${ }^{2}$. Una descripción detallada sobre el asesinato de Sandino se encuentra en Gregorio Selser, Sandino, General de Hombres Libres, Ed. Universitaria Centroamericana, San José, 1980, pp. 293-300, la obra clásica sobre la vida y pensamiento de Sandino. Selser cita las siguientes palabras de Anastasio Somoza, responsable directo de ese asesinato: "Vengo de la embajada americana donde acabo de sostener una conferencia con el embajador Arturo Bliss Lane, quien me ha asegurado que el gobiemo de Washiington respalda y recomienda la eliminación de Augusto Cesar Sandino, por considerarlo un perturbador de la paz del país”, citado p. 293.
} 
octubre de 1967 a sangre fría y a mansalva por ordenes directas de la CIA y del gobierno de Estados Unidos de Lindon B. Johnson ${ }^{3}$, son presentados como muertes a secas, queda la impresión que aquellos fueron muertes en combate o fallecieron de muerte natural. Así mismo, decir que la resistencia de Sandino fue hecha con guerrilleros latinoamericanos es reducir la importancia de la lucha de los nicaragüenses contra la ocupación norteamericana, e insinuar que la participación popular fue mínima.

Y cuando se presenta el golpe criminal en Guatemala en 1954, financiado, organizado, preparado y asesorado por el gobiemo de Estados Unidos -como hoy todo el mundo lo sabe y lo han revelado los propios archivos norteamericanos ${ }^{4}$ - se dice, de una manera aparentemente inocente, que Arbenz renunció, y para justificar esta impresión (por no decir falsedad), inmediatamente se sostiene que durante ese gobierno hubo "influencias marxistas". Como quien dice era justificado el golpe de Estado preparado por la CIA. Tal fue el argumento, mil veces repetido del gobiemo de Estados Unidos de la época, que acuso a Jacobo Arbenz de ser una quinta columna comunista en Centro América que ponía en peligro la paz del continente y la seguridad de Estados Unidos. Con tales argumentos, en la época se saboteó a ese gobiemo democrático y se intentó legitimar el golpe que lo derroco ${ }^{5}$.. En cuanto a lo sucedido en Chile, es difícil creer que el 11 de septiembre solamente se haya presentado un sublevamiento militar, cuando en realidad se perpetró uno de los golpes más sangrientos de la his toria continental ${ }^{6}$. Finalmente, decir que Grenada fue ocupada por culpa de la subversión soviéticocubana, es limitarse a repetir el argumento del gobiemo de Reagan ${ }^{7}$. Un historiador no puede invocar tranquilamente un argumento de esta categoría como la justificación de un acontecimiento

\section{Geopolítica, superpotencias e historiografía: una extraña manera de demostrar la validez de una escuela histórica}

Los dos primeros capítulos, introductorios a la exposición general sobre la historia de América Latina, pretenden precisar cuestiones sobre metodología, teoría e historiografía. El primer capítulo, que lleva el título "Diversas lecturas de la historia", tiene por objetivo clarificar las principales tendencias historiográficas que, según Chevalier, existen en América Latina. Entre las tendencias escogidas

\footnotetext{
${ }^{3}$. Hoy en cualquier biografia del Che, se reconocen las condiciones de su asesinato, a sangre fría y en forma cobarde por parte de verdugos del ejército boliviano cumpliendo ordenes expresas de la CIA. Ver, por ejemplo, Jai me Jerez, Che Guevara, Grandes protagonistas de la humanidad, Editora Cinco, Bogotá, 1985, pp. 234 y ss.

${ }^{4}$. Al respecto ver el extraordinario libro de Stephen Schlesinger y Stephen Kinzer, Fruta Amarga. La CIA en Guatemala, Siglo XXI Editores, México, 1982. Este libro ha sido elaborado a partir deinformación delos archivos de Estados Unidos. 5. P or ejemplo el 19 de mayo de 1954, es decir menos de dos meses antes del golpe organizado por la CIA, el presidente Dwigh Eisenhower dijo que Guatemala era " una avanzada comunista en el continente”, Ibid, p. 25.

6. Ver, Carlos Rama, Chile: Mil días entre la revolución y el fascismo, Ed. Planeta,

7. Recientemente el historiador inglés Cristopher Andrew publico un libro titulado, Solo para los ojos del presidente. La inteligencia secreta y la presidencia de Estados Unidos desdeWashington hasta Bush. La traducción de varios apartes de este documentado libro fue publicada por la revista Proceso de México del 1 y 8 de enero de 1996. Este autor cita las palabras de Regan y el Director de la CIA, William Casey, que consideraron que Grenada era "una colonia soviéticocubana que se destinaba a ser un bastión militar de importancia para exportar el terror y socavar la democracia", Proceso, 18 de enero de 1996, p. 51. 
se encuentran el Marxismo, la escuela francesa, y la historiografía de Estados Unidos. Respecto a la primera, el autor considera solamente las obras de historiadores de la antigua URSS. Su análisis, bastante pobre y poco exhaustivo, se ocupa fundamentalmente de la influencia de la Perestroika, combinando en una forma bastante ambigua e improcedente dos tipos de hechos diferentes: su impacto real sobre diferentes sociedades, como Cuba, y su influencia en el plano del conocimiento. Señala que "había cierta convergencia entre los puntos de vista de las dos superpotencias victoriosas: materialismo histórico en la URSS y en los Estados Unidos interés particular y tradicional por los temas económicos" (p. 142). Para Chevalier la importancia de una determinada tendencia histórica está directamente relacionada con el peso geopolítico de una potencia. Esta es una apreciación muy pobre y muy mecánica que no tiene en cuenta, de ninguna forma, la riqueza del conocimiento en general y del materialismo histórico en particular. En su afimación se reduce tanto el materialismo histórico a la versión soviética como la historiografía norteamericana a la historia económica. No creo que ni en Estados Unidos ni incluso en la Rusia actual estén de acuerdo con una clasificación tan esquemática. El autor concluye que la Perestroika ha modificado la apreciación marxista de la his toria (p.148) sin dar razones justificadas des de el punto de vista del conocimiento histórico ni de las diversas tendencias del materialismo histórico.

Si bien es cierto que la Perestroika como proceso político tuvo que ver con la crisis de un modelo de socialismo y eso produjo desconcierto mundial, es demasiado estrecho el pretender que por esa razón toda la historiografía marxista dejo de existir o está en curso de desaparecer. Además, en el caso de América Latina no queda claro cual fue el efecto final de la Perestroika, salvo en el caso de Cuba donde los vínculos económicos con el antiguo bloque de Europa Oriental eran evidentes. Pero en el resto del continente el impacto de la Perestroika fue marginal. Y si eso fue así en el caso de los procesos políticos particulares, difícilmente de ahí puede sacarse la conclusión que la his toriografía marxis ta, mas variada y amplia de lo que pretende Chevalier, quedo herida de muerte.

A propósito de las investigaciones históricas de Estados Unidos, Chevalier piensa que existen numerosas contribuciones, sobretodo de la New Economic History. Esta, a diferencia del Marxismo que "retrocede en el mundo" (p. 148), es muy importante "como conviene a la única superpotencia que toma conciencia de su papel esencial en el mundo" (p. 152). O sea que la historia, en este caso, solo tiene importancia si está ligada al poder y mas si es el poder de una potencia mundial. Se supone que en caso contrario, por ejemplo si Estados Unidos no fuera la primera potencia del mundo, no tendría jus tificación que en ese país se llevaran a cabo investigaciones históricas. Es difícil encontrar una afimación más carente de sentido. Por lo demás, este argumento, de naturaleza geopolítica antes que teórica, confima la importancia que Chevalier le asigna a las potencias en el conocimiento histórico y no es muy convincente ni para explicar la crisis del marxismo ni tampoco la importancia de la historiografía de los Estados Unidos. En nuestra opinión este asunto, propio de una sociología del conocimiento histórico debe ser examinado con relación a la estructura teórica y metodológica de cada 
tendencia, olvidándose de los factores geopolíticos, que son contingentes y episódicos, como lo fue la Perestroika y como a no dudarlo lo será el reinado mundial de Estados Unidos.

La otra tendencia historiográfica considerada en el primer capítulo es, naturalmente, la escuela francesa de los Anales y las últimas contribuciones de la historia cultural, política y de las mentalidades, es decir esa mezcolanza de moda que se llama la Nouvelle Histoire. Desde luego, esta pers pectiva analítica es la que adopta François Chevalier para escribir su libro. Resulta bastante extraño que cuando hable de la historiografía francesa, Chevalier no intente como en los casos de la antigua URSS -ligada a la historiografía marxista- o de Estados Unidos vinculada a la historia económica- relacionar la situación de Francia como potencia y el rol de su disciplina histórica y de sus historiadores. Aquí, Chevalier sigue una tradición muy francesa, que consiste en preocuparse y criticar a los demás pero negarse a considerar su propia situación. Si él hubiera aplicado al caso de Francia el mismo tipo de razonamiento que propuso para la historia marxista, tranquilamente podría concluir, por ejemplo, que la escuela de los Anales debería haber muerto junto con la desaparición del im perio colonial francés o con el fin del gobierno de Charles de Gaulle a fines de los años 60. Tanto Chevalier como cualquier historiador francés de seguro se escandalizara con una afimación de esta naturaleza, pero no con la de vincular la supuesta muerte de la historiografía marxis ta al fin de la URSS.

En este primer capítulo se observa una aus encia increíble: aunque el tema del libro es la historia latinoamericana, no hay un solo comentario sobre las obras de los propios historiadores del continente. Por supuesto, hay referencias tanto en la bibliografía como en los capítulos del libro, pero el autor no hace ninguna consideración analítica sobre las tendencias historiográficas que existen en los diferentes países de América Latina. Así, un lector desprevenido pensara que actualmente en ningún país de la región existe una historiografía propia. Visto en la perspectiva del autor, de ligar la importancia de una explicación histórica a una potencia: el marxismo a la URSS, la New Economic History a los Estados Unidos y la Nouvelle Histoire a Francia, es apenas lógico que ni mencione a la historiografía latinoamericana, pues como sencillamente América Latina no es una potencia se infiere que no tiene una producción histórica ni propia ni significativa. Tal es la obvia consecuencia de una visión geopolítica de la producción historiográfica, visión que, des de luego, es elitis ta y eurocentrista.

\section{Balbuceos teóricos}

En el segundo capítulo, el más teórico de todo el libro, el autor define la estructura interna de su exposición. Explica la importancia de la economía, de la geografía, de la demografía, temas de la primera parte del libro. Después, subraya el valor de las nuevas investigaciones de Etnohistoria y de Antropología y considera también el estudio de la cultura, as pectos todos de la segunda parte del libro. Finalmente, indica las contribuciones de la historia de la política para comprender las características de la modernidad en América Latina. Esta 
"explicación teórica" no tiene la más mínima consistencia ni orden, es simplemente un conjunto desarticulado de puntos de vista sobre diversos tópicos y, en el mejor de los casos, es un resumen de las investigaciones de ciertos autores franceses contemporáneos, que han escrito de Antropología y etnohistoria. Precisamente, esta amalgama explicativa, desordenada y, por momentos, sin ningún sentido se reproduce en cada capítulo, lo que convierte en toda una odisea, un verdadero sacrificio para el espíritu, el leer un material tan denso y árido. Por lo demás, estas son explicaciones absolutamente innecesarias en un libro de síntesis, que se supone es tá dirigido a un público amplio y no especializado.

\section{5. "Explosión demográfica" y debilidad in dígena para adaptarse al medio}

Considerando los temas precedentes, a partir del tercer capitulo, François Chevalier por fin nos empieza a ilustrar con su versión de la historia latinoamericana desde la independencia. En una primera parte (Cap. III: Demografía, Cap. IV: Economía, Cap. V: Economías de exportación, pp. 191-278), expone las características generales del desarrollo demográfico y económico de América Latina. Sobre la demografía, considera que el problema esencial del continente es la "explosión demográfica" (p. 194-201), un término en si mismo cuestionable e impreciso, cuyo origen se encuentra en la reducción de la tasa de mortalidad, debido a la desaparición de las epidemias, a la disminución de la mortalidad infantil y las enfermedades endémicas, tales como la malaria o las infecciones intestinales (p. 95). Al parecer en esta parte del libro, al profesor Chevalier se le olvido que estaba hablando de América Latina, pues si se observan las informaciones sobre la situación actual del continente en materia de salubridad, es notorio observar el recrudecimiento de todas las circunstancias que, según él, habría desaparecido o se habrían reducido sensiblemente. Las epidemias, la mortalidad infantil, la gastroenteritis siguen siendo una cruda manifestación de la pobreza y la miseria de América Latina ${ }^{8}$.

Para completar, en una muestra de un cierto deteminismo geográfico, Chevalier afirma que en algunas regiones del trópico húmedo "la regresión o la desaparición de las poblaciones indígenas después de la conquista española (a veces antes) debe explicarse por una menor resistencia del organismo al medio" (p. 207). Resulta que ahora a Chevalier, le debemos una nueva explicación sobre la reducción de los pueblos indígenas, que no ha sido causada ni por el colonialismo, ni por la expansión occidental, ni por el genocidio sis temático al que esos grupos han sido sometidos durante más de cinco siglos, sino que es un resultado de su dificultad para adaptarse a las condiciones del trópico húmedo. ¡¡Para dar una explicación tan "científica” no es necesario vivir en París!!

\footnotetext{
8. Roberto Díaz, “El significado mundial de Chiapas: racismo, democracia y propiedad en el proyecto neoliberal”, en N. Chomsky et al, Chiapas Insusrgente, 5 ensayos sobrela realidad mexicana, Ed Txalaparta, Tafalla, 1995, pp. 146-154. 


\section{Una Apología histórica del neoliberalismo de Salinas de Gortari que naufrago tan rápido como el "milagro mexicano"}

En el cuarto capítulo, Chevalier analiza la evolución económica del continente, precisando las variables estadísticas más importantes, es decir los precios, los salarios, la renta, la productividad, el crédito, y las inversiones. Con esas variables, hace un estudio bastante desigual. En los paragrafos consagrados a los precios y al crédito el análisis es muy detallado, mientras que al considerar el salario y la renta los elementos aportados son muy limitados. La mayor parte de los temas abordados en este capítulo están centradas en el siglo XIX, o en el caso de la evolución de los precios hasta la Gran Depresión de los años treinta. Del anális is de las inversiones, que llega hasta 1914, bruscamente sin ninguna línea de continuidad analítica ni histórica se pasa al problema de la deuda externa latinoamericana, sin explorar sus causas, su origen y su desarrollo. Los pocos aspectos que se consideran sobre la deuda externa del continente no son analizados críticamente, teniendo en cuenta su impacto negativo sobre la economía y la sociedad.

El autor simplemente se limita a dar información estadística, sin profundizar ni en el manejo político del problema de la deuda ni en la implementación de los planes de ajuste estructural y sus consecuencias. Pareciera ser que América Latina hasta ahora no ha conocido este tipo de ajustes. Chevalier está más interesado en resaltar la "solución neoliberal" al problema de la deuda, para lo cual elogia de una forma ditirambica el caso mejicano, y sobretodo la política adelantada por Carlos Salinas de Gortari. Al respecto, tomando el caso de México como un modelo que hace extensivo al resto del continente, afirma que "las nuevas políticas, particulamente comerciales...tienden a hacer de la deuda un problema diferente" en un marco en el cual América Latina ha "recobrado el crecimiento económico" (p. 233). Hoy, después de la crisis financiera de México en enero de 1995, cuyas consecuencias están a la vista del todo el mundo (devaluación forzada, un millón de nuevos desempleados, crisis del aparato productivo y un impresionante aumento de la deuda exterior en 50.000 millones de dólares $^{9}$ ), tan optimista afimación sobre las relaciones entre la deuda y el crecimiento económico no sólo dejó de tener sentido sino que se demostró falsa, como los recientes hechos lo han demostrado fehacientemente. Volveremos sobre esta cuestión enseguida.

El quinto capítulo intenta delinear una historia del sector exportador de América Latina. Se hacen una serie de consideraciones sobre los diferentes productos que desde la independencia hasta el día de hoy han jugado un rol crucial: el café, el guano, el azúcar, el petróleo. Casi la mitad del capítulo tiene por objeto el estudio de aspectos contemporáneos, tal es el caso de las maquiladoras en México. François Chevalier piensa que la consolidación de las maquiladoras es un hecho económico ampliamente favorable para México y los Estados Unidos. A partir de

\footnotetext{
${ }^{9}$. Ver para un análisis de la crisis mexicana, Noam Chomsky et al., op. cit., pp 207-209; Varios, De la revolte de Chiapas à la crise financière, Future Anterieur,P aris, 1996. 
esta importancia, el autor manifiesta su complacencia con la política mexicana y más especialmente con el Tratado de Libre Comercio. Explica que "bajo la presidencia de Carlos Salinas de Gortari, México ha dado los más grandes pasos por restablecer una economía sana con los ajustes necesarios” (p. 265). ¡iUna economía tan sana, que solo necesito la inyección de 50.000 millones de dólares del sistema financiero internacional, para enfrentar la crisis a comienzos de 1995, cuyo impacto inmediato fue la hipoteca de los principales renglones de la actividad económica y productiva de México!! En igual sentido, en las conclusiones del libro reafima que el neoliberalismo del presidente Salinas le permitió desarrollar una "política más social" (p. 674).

Es difícil encontrar una apología más vulgar del gobierno de Salinas de Gortari, cuya presidencia hundió a México en la crisis económica y social más importante del siglo $X X$, después de la de los años treinta. Hoyse sabe que la situación actual de México es más difícil que antes de la adopción de las políticas neoliberales, tal como los expertos económicos del mundo entero lo reconocen ${ }^{10}$. México, el caso más ejemplar del éxito económico según los neoliberales y según el historiador François Chevalier, es considerado en la actualidad como el proceso más negativo de la historia reciente del mundo, por sus consecuencias económicas y sobretodo sociales. El sueño neoliberal de Gortari y del historiador Chevalier, para millones de mexicanos se convirtió en una auténtica pesadilla.

Siguiendo con su línea de razonamiento, las maquiladoras son presentadas como un gran logro, tanto para México como para Estados Unidos, principalmente porque allí se pagan salarios entre 10 y 14 veces más bajos que los que las compañías norteamericanas pagarían en su propio territorio (p. 265). A partir de tan halagadora constatación, es entendible que Chevalier no tenga en cuenta para nada el sistema de explotación de la fuerza de trabajo mexicana en las maquiladoras, en las cuales no existe ni protección laboral ni social y cuyo efecto sobre el empleo global del país es mínimo ${ }^{11}$. Chevalier expresa su complacencia con la generalización del capitalismo maquilero como lo haría cualquier neoliberal latinoamericano, cualquier invers ionis ta extranjero o cualquier multinacional.

Su aprobación de las maquilas llega hasta el punto de sugerir que Francia debería desarrollar un sistema similar al de México en territorios como Argelia. Con una tranquilidad pasmosa, afirma: "En México, la multiplicación de maquilas ha sido un primer test de integración aparentemente favorable a las dos partes, en particular para México que evita así la partida fuera de sus fronteras de una mano de obra excedentaria. Un ejemplo que podría inspirar acuerdos franco-argelinos" (p. 675). Es decir que para Chevalier, el capitalismo maquilero debería generalizarse no sólo en los países de América Latina sino incluso debería

\footnotetext{
${ }^{10}$. Incluso Milton Friedman, el pontífice del neoliberal ismo se vio obligado a reconocer que en México se desató una crisis, aunque haya dicho que solo fue por culpa de una política monetaria equivocada. Ver:, Pascal Beltran del Rio, "Milton Friedman, creador del neoliberal ismo, sale en su defensa: el error de México fue la política monetaria", Proceso, 22 de enero de 1996, p. 26.

${ }^{11}$. Rodolfo Stavenhagen, "Democracia, modemización y cambio social en México", Nueva Sociedad, No. 124, marzoabril de 1993, p. 33.
} 
extenderse a todo el mundo pobre y así, según su cándida visión, se solucionarían los problemas de migración de los país es del Sur hacia los países ricos. Su caso arquetipo, siempre México, otra vez desmiente su optimismo, pues en los últimos años la migración de mexicanos hacia Estados Unidos en lugar de disminuir se ha acrecentado, como resultado de la crisis económica y del impacto negativo del TLC sobre la economía mexicana ${ }^{12}$.

\section{Estados Unidos: una mansa e inocente paloma en el negocio del Narcotráfico}

En el quinto capítulo también se hacen algunas anotaciones sobre la producción de cocaína, el rol de los carteles y la corrupción política. La discusión comienza cuando se aborda el tema del cons umo. Chevalier afirma, en una forma trivial, que antes de 1989 "se consideraba que el problema de la droga era en principio el de los consumidores -los Estados Unidos en primer lugar- y no el de los productores, que no hacían sino satisfacer la demanda...Por cuestiones de interés, como por razones ideológicas -el rechazo del 'imperialismo yanqui'"'-los Estados no estaban muy urgidos para actuar" (p. 270).

Estas afirmaciones no tienen mucho fundamento, en la medida en que no se trata de inculpar a los Estados Unidos como el responsable principal del negocio de las drogas solamente por expresar un rechazo o una oposición visceral al "imperialismo yanqui". Tal explicación expresa una actitud paranoica de Chevalier, pues acusa a los gobiernos latinoamericanos de adoptar posiciones antinorteamericanas respecto a la cuestión de la droga, algo que precisamente ni por asomo les han pasado por la cabeza. Por eso, sostener que entre los gobiernos latinoamericanos afectados por el problema de la droga ha habido un rechazo al "imperialismo yanqui" no tiene el más mínimo fundamento. La cuestión es un poco más simple: el mercado norteamericano de narcóticos es, sin ninguna duda, el más importante del mundo, y por consiguiente la demanda de ese mercado es la principal razón, aunque desde luego no la única, que induce a la producción de cocaína en los países andinos ${ }^{13}$.

Cuando se refiere a la "nueva política" de Estados Unidos frente a la droga, Chevalier considera que "las recientes evoluciones de la geopolítica mundial dan a

\footnotetext{
12 . Ver Sylvie Laporte, “Trois ans après, les comptes de l'Alena”, en Volcans No. 23, Septiembre 1996, pp. 5-7.

${ }^{13}$. Incluso alguien como Milton Friedman, que sepuede calificar de todo menos de enemigo del "imperial ismo yanqui" ni de aliado de los países pobres, ha dicho con respecto a la responsabilidad de Estados Unidos en el negocio de la droga:

"En su intento por prohibir el consumo de drogas...el gobierno de Estados Unidos ha promovido el crimen y la violencia en este país y, peor aún desde el punto de vista moral, nuestra política ha causado la muerte de miles de personas en Colombia, en Perú, en México...Está claro que la llamada guerra contra el narcotráfico es un fracaso y ha sido más dañina que benéfica. Yo objeto el daño que estamos haciendo a otros países, por el hecho de no poder aplicar nuestras propiasleyes.

Si pudiéramos aplicar nuestras leyes contra el consumo de drogas, no habrían problemas con un Cártel de Cali o un Cártel de México o por el hecho de que la policía mexicana detiene a un capo del narcotráfico y lo manda a Estados Unidos. Esas cosas no existirían si aplicáramos nuestras propias leyes. Yo quiero saber como se justifica, moral y éticamente, i mponer esos costos a países extranjeros", Pascal Beltran del Río, op. cit, p. 27, subrayado nuestro. Un análisis de la política de Estados Unidos en materia de narcortráfico se encuentra en Marcos Kaplan, "Tráfico de drogas, soberanía estatal y seguridad nacional en América Latina”, El Cotidiano No 71, septiembre de 1995, pp. 109 y ss.
} 
los Estados Unidos más libertad para actuar sobre los circuitos de la droga, que consideran... ligados a los fenómenos de subversión política (guerrillas y regímenes de Cuba... y Nicaragua). Ya no es la época en que el gobiemo americano se acomodaba en Panamá, en Haití o en otros lados a regímenes ligados al tráfico, como se ha visto en diciembre de 1989 con la caída del general Noriega en Panamá. La ayuda suministrada a Colombia, el apoyo al gobiemo mexicano....muestran que la droga se ha convertido en una cuestión política internacional, en una América que no conoce ya los enfrentamientos ideológicos de los últimos treinta años" ( $p$ 271).

Al ver estas líneas se tiene la impresión de estar leyendo un anális is de la DEA o el discurso de un presidente norteamericano, en plena campaña electoral, porque no se pueden involucrar tantas falsedades en un solo párrafo. Insinuar que los gobiernos de Cuba y el gobierno sandinista estuvieron involucrados en el tráfico de drogas solo revive los argumentos típicamente anticomunistas y bélicos de los gobiemos de Estados Unidos y sus voceros. Lo único que le falto evocar al profesor Chevalier fueron argumentos como aquellos inventados en Estados Unidos, y patrocinados por la prensa norteamericana, en los que se dice que el Ministro de Defensa de Cuba, Raúl Castro, hermano de Fidel Castro, personalm ente ayuda a cargar y descargar los aviones con droga que aterrizan en $\mathrm{Cuba}^{14}$. Sobre lo de los sandinistas, hoy se sabe que las acusaciones criminales de la administración Reagan que comprometían al gobierno sandinista por sus supuestos nexos con el narcotráfico, eran una vil calumnia. Por contra, quienes planearon y facilitaron el tráfico de droga en el territorio de Estados Unidos -con el cual intoxicaron a los habitantes negros de ciertos de sus Estados-, fue el gobiemo de Reagan para financiar a los contras nicaragüens es ${ }^{15}$. Era necesario suminis trar estos datos para demostrar la falsedad de tales insinuaciones.

Además, pensar que el gobierno norteamericano invadió y masacró al pueblo de Panamá en 1989 -cosa que no dice Chevalier, pues para él Noriega "cayo", como si hubiera caído del cielo- simplemente para capturar y juzgar a un narcotraficante que antes había sido agente de la CIA, es dar muestra o de una ingenuidad histórica impresionante o de una complacencia descarada con la política de Estados Unidos. Porque en el caso de Panamá, no se puede desconocer que el objetivo fundamental era destruir la Guardia Nacional y colocar autoridades incondicionales al servicio del gobierno norteamericano en vista de la proximidad de la devolución del canal a los panameños ${ }^{16}$. Nada de esto, parece existir para la sensibilidad histórica de Chevalier, presto a recibir sin ningún inventario crítico la versión oficial de la política norteamericana en el continente.

\footnotetext{
${ }^{14}$. Tan ridícula patraña, urdida conjuntamente entre la prensa y el gobierno de Estados Unidos es relatada en el libro de Román Orosco, Cuba Roja, Javier Vergara Editor, Bogotá, 1993.

15. El periodista norteamericano Gary Webb recientemente descubrió que la CIA patrocinó la más grande organización de distribución y venta de droga en los propios Estados Unidos. Así, la generalización del consumo de Crac en Estados Unidos estuvo asociado a la guerra criminal librada contra el gobiemo sandinista, puesto que la CIA encubrió las redes de Daniel Blandón, vocero de los Contras nicaragüenses. Con las ganancias Blandón pudo organizar un ejercito de 5000 mercenarios en Nicaragua. Ver: "La CIA, el cartel intocable", El Espectador, 23 de octubre de 1996, p. 1E.

${ }^{16}$. Noam Chomsky, Las intenciones del Tio Sam, Ed Txalaparta, Tafalla, 1994, p. 45. 
No de otra forma se entiende, que Chevalier ahora nos diga que los "Estados Unidos ... parecen decididos a actuar más eficazmente" en la lucha contra la droga. (p. 270). Habría que ver en el caso de Estados Unidos que se entiende por luchar eficazmente contra la droga. Una cosa es reprimir a los países productores, fumigando los cultivos de los campesinos cocaleros, aumentando la intervención militar con el pretexto de reprimir a los Carteles o a los capós del negocio, controlando el sistema financiero de los países productores o bloqueando sus costas. Otra cosa distinta es no hacer nada para enfrentar el problema interno de la droga, como ha sido indistintamente la política antidroga de los gobiernos de Estados Unidos.

\section{De como los pueblos indios deben estar agradecidos con los beneficios que les ha traído la "modernidad"}

En la segunda parte del libro, Chevalier pretende analizar la heterogeneidad social del continente. El capitulo $\mathrm{VI}$ aborda la cuestión de la etnohistoria. Respecto a las comunidades indígenas, se afirma que estas sólo pueden ser comprendidas y definidas en una perspectiva histórica (p. 289), por lo que debe considerar la importancia de la dominación española y de su herencia. Después de hacer un relato de algunos aspectos de esta historia, el autor plantea que el problema esencial de los pueblos indios en el mundo actual radica en: "como respetar una personalidad original pero de tipo comunitario sin sacrificar lo que puede aportar a los indígenas una modernidad fundada ampliamente en el individuo" (p. 298).

Esta afimación es muy parecida a la que hace algunos años hizo Vargas Llosa, en el sentido de que "tal vez no hay una manera realista de integrar nuestras sociedades sin pedir a los indios pagar un precio alto: renunciar a su cultura, lenguaje y creencias. Si fuera forzado a escoger entre las culturas indias y su asimilación completa con gran tristeza escogería la modemización..." ${ }^{17}$ Hasta donde sabíamos, el problema de los grupos indígenas es justamente lo opues to a lo planteado por Chevalier y Vargas Llosa, ya que la "modemidad" ha sido y es la fuerza des tructora fundamental que los ha aniquilado y los sigue aniquilando has ta el día de hoy. Sin embargo, en la perspectiva eurocéntrica son los pueblos indígenas los que tienen que adaptarse a la modernidad depredadora y no esta la que debe respetar sus tierras, su cultura, su identidad y sus valores ancestrales. ¡¡Bonita forma de considerar el respeto a la diversidad, todo en nombre de los supuestos valores de la modernidad capitalista!! Contra es os valores criminales se levantaron los indígenas de Chiapas, un caso mejicano que al "mejicanista" Chevalier nunca le pasó por la cabeza y que de seguro le molestaría como molestó al gobierno de su ídolo neoliberal Carlos Salinas de Gortari.

17. Mario Vargas Llosa, "Palabras de Conquista”, citado en Evaristo Nugkuag, “AAutodeterminación o asimilación. Respuesta a Mario Vargas Llosa?", en IW GIA BOLETIN, No. 1, julio-agosto de 1991, Grupo internacional de trabajo sobre asuntos indígenas, p. 30. 


\section{Bienaventurados los militares que restauraron el orden}

En capítulo VI también hay un análisis ulterior del caudillismo y una pequeña nota sobre los militares. En este paragrafo, el autor hace un recuento general del militarismo en la historia de América Latina desde el siglo XIX hasta el momento actual. Sin embargo, dicho recuento es tan pobre que ni menciona el papel jugado por los ejércitos del continente en el período 1964-1990, cuando la mayor parte de los país es de la región es tuvieron sometidos a dictaduras militares, a nombre de la doctrina de la Seguridad Nacional. Como consuelo, el autor agrega lacónicamente que "es evidente que el rol político de los generales no es un fenómeno puramente ibérico: la multiplicación de gobiernos en el mundo lo muestra bien”. (p. 331) ¡!Mal de muchos, consuelo de tontos!!, dice un viejo y sabio adagio popular, que se aplica al pie de la letra a Chevalier, porque su afimación no explica nada. Un historiador no puede contentarse con la contem plación de un fenómeno, el debe explicarlo, buscar su causalidad y su dinámica es pecífica. Además, una afimación de esa índole supone una justificación histórica de las dictaduras militares del continente, porque olím picamente se puede pensar que si ellas existieron en otros lugares del mundo estaban de sobra justificadas en América Latina. Y esa justificación adquiere todavía un tono más claro, cuando François Chevalier, en forma de seudopregunta, explica porque se extendieron las dictaduras en el continente: "¿la general contestación de toda autoridad o valor tradicional no provoca ciertas reacciones favorables a la disciplina y al orden de las amas?", es decir que las criminales dictaduras del continente, en América Central y en Sudamérica, fueron una respuesta al desorden reinante en estos países. ¡Conque las dictaduras de Somoza, Duvalier, Pinochet y compañía fueron una respuesta a la general contestación de toda autoridad, vale decir al descontento de los pueblos contra la injusticia y el capitalismo!

\section{El atraso de América Latina se debe a su complejo de subdesarrollo y dependencia}

En una tercera parte del libro se estudia la Cultura, los Valores y los Comportamientos. El capítulo IX (Ideas fuerza y Sociabilidades, Educación) en gran parte estudia el siglo XIX, subrayando la función del liberalismo y del conservatismo. De la misma manera se analiza el caso del positivismo en México, el agrarismo, el indigenismo, y el utilitarismo. En un pequeño paragrafo se menciona el rol del anarquismo, de los socialismos y del marxismo. El capitulo finaliza con algunas consideraciones sobre la educación y el rol de las universidades, sobretodo a partir del movimiento universitario de Córdoba en 1918. Mas de la mitad de este capítulo es tá consagrada al siglo XIX (pp.415-443) y el caso de México ocupa un tercio del capítulo (pp. 424-437). Hay un paragrafo en el que se recogen aspectos tan variados como el anarquismo, los populismos, los socialismos y el marxismo que es completamente superficial. Se mezclan las ideas de todo con todo, es tudiando preferentemente el caso de México. En el caso del Marxismo no se hace un anális is de su recepción ni se menciona el caso de Mariátegui, obligatorio cuando se hable del marxismo latinoamericano. El tema es cerrado con esta perla: "El marxismo-leninismo, el nacionalismo, y las 
frustraciones han hecho prevalecer allí la imagen de la dependencia de un continente víctima y presa del imperialismo. Esta explicación del subdesarrollo del continente por un factor externo tiene como punto de partida hechos patentes: acreditado ya en los medios europeos, ella se impone como un artículo de fe en América Latina. El concepto toma la talla de un mito o de un mesianismo, consustancial al medio intelectual en causa y al factor histórico que representa. De ahí surgen profetas, santos y mártires: un Fidel Castro que habría extirpado el mal, un sacerdote Camilo Torres quien ha sido la víctima... y sobretodo el Che Guevara, el guerrillero carismático, modelo del 'hombre nuevo' y mensajero de la edad de oro por venir" (p. 448).

Nuevamente nos encontramos con una de esas muestras de profundidad analítica de Chevalier y su auxiliar. Porque resulta que, de una parte, la dominación imperialista es solo una construcción arbitraria de los marxistas y nacionalistas, y no ha sido un hecho histórico real en el continente; de otra parte, esa idea sólo cobró fuerza porque fue "patentada" por los intelectuales europeos, pues ni siquiera los latinoamericanos fueron capaces de producirla (como sí la Teoría de la Dependencia no se hubiera originado en América Latina sino en las aulas europeas). Además, decir que solamente por la idea de dependencia surgieron figuras como Fidel Castro, Camilo Torres o el Che es un perfecto disparate. Porque explicar fenómenos sociales, políticos y simbólicos de la magnitud que representan los tres personajes mencionados no se puede hacer en una forma tan ordinaria -un procedimiento muy similar al empleado por tres mosqueteros del Imperio que recientemente publicaron un panfleto de pornografía política apadrinado por el escritor de extrema derecha Mario Vargas Llosa- sin considerar la especificidad de cada proceso his tórico en el que discurre la vida de esos individuos. Ni la revolución cubana, ni la muerte de Camilo Torres ni la lucha del Che pueden ser caricaturizadas en una forma tan mezquina, desconociendo la vitalidad de cada proceso histórico y las razones que en su momento llevaron a luchar a esos hombres, las que no se pueden reducir a una simple invención febril de cada uno de ellos.

\section{A favor del Vaticano contra la Teología de la Liberación o de como estar siempre con los vencedores y poderosos}

El análisis que sigue sobre la educación termina en 1910 y se concentra otra vez en México. Tan fuera de contexto y de rigor expositivo andan los autores que en lugar de indagar sobre la historia reciente de la educación en América Latina terminan preguntándose si el atraso no se debería a la "ausencia de la matemática cartesiana" en la época de la dominación española (p. 457). Una afirmación absolutamente fuera de contexto, que se remite a un período que no tiene una relación directa con el problema que se pretende historiar, el de la educación en el siglo XIX y XX. Si se quería enfatizar el impacto de la educación confesional, católica y sectaria, tranquilamente, sin recurrir a ese tipo de preguntas con aires de suficiencia, se habría podido estudiar el desarrollo de la educación con sus propios problemas en América Latina durante el siglo $X X$. A respecto no hay ni una palabra. Con ejemplos como el antes citado, queda la impresión que la 
incapacidad por estudiar un tema se le sustituye por afirmaciones sueltas, sin ningún tipo de contextualización.

En el capitulo $X$ se estudia la religión, un hecho muy importante en la his toria de América Latina. Se encuentran una serie de anális is sobre la iglesia católica y sus instituciones a partir de la herencia ibérica y durante el siglo XIX. También hay un paragrafo consagrado a la Teología de la Liberación y otro a la ola protestante que recorre el continente. Como era de esperarse, en el texto se encuentra una crítica abierta a la Teología de la Liberación, que no podía faltar en este libro teniendo en cuenta las perlas que antes hemos mencionado. Lo sorprendente del caso es que la crítica a la Teología de la Liberación se haga repitiendo y compartiendo las tesis del Vaticano. De entrada, los autores como buenos eurocentristas que son, consideran que la Teología de la Liberación no es un producto latinoamericano, sino una concepción de "orígenes europeos", puesto que algunos de los sacerdotes que luego participarían en su elaboración habían estudiado en universidades del viejo continente (p. 472). Que superficialidad. ¡Nada se puede originar en el resto del mundo, sino es a partir del pensamiento europeo! No importa que Gus tavo Gutiérrez, un sacerdote peruano nutrido intelectualmente de la propia tradición cultural de su país, haya sido el primero que teóricamente fundamento el concepto en $1971^{18}$.

Definitivamente no hay derecho, por una parte, a que se niegue la autenticidad de un proyecto no solo teológico sino intelectual, social y político como la Teología de la Liberación y que, además, por otra parte, en una obra académica -que debería ser seria- se utilicen como base crítica de esa teología los documentos oficiales del Vaticano, redactados por el cardenal Ratzinger. De ahí se concluirá olímpicamente que la Teología de la Liberación no representa nada nuevo, pues solo es una ampliación del Vaticano II, y además se propone que esa teología pierda sus "excesos" (p. 473), entre los que se encuentran al marxismo -aunque se diga allí que "la tentación por el marxismo que pierde crédito ya no es un verdadero peligro" Esos excesos son, por supuesto el compromiso político militante por los pobres del continente. Des de luego, que si esa es la base de la crítica, no es raro que Chevalier y su auxiliar teminen haciendo una apología descarada del Vaticano y en especial de Juan Pablo II. Hasta el punto que tienen el desparpajo de aplaudir el hecho de que finalmente en Nicaragua se haya impuesto la "lógica vaticana de la larga duración" -cuyo objetivo era lograr que los 4 ministros sacerdotes se retiraran del gobierno sandinista- lo que finalmente se logró pues el gobierno nicaragüense cambió de manos (p. 475)

\section{Esas insignificantes revoluciones}

En la última parte se considera el tema de los desequilibrios políticos y sociales en dos extensos capítulos: el XI: Crisis, Sublevaciones y Revoluciones y el XII: Estado, Nación, Sistemas Políticos. En el capítulo XI el autor analiza la historia de

\footnotetext{
${ }^{18}$. El mismo Gustavo Gutiérrez reivindica su filiación con el pensamiento social peruano, y fundamentalmente con José Carlos Mariátegui. Ver: “ Mariátegui y Gutiérrez”, entrevista, Pretextos, No. 7, 1994, pp. 109 y ss. 
los cambios políticos, de los cuales "América Latina representa un campo excepcional de observación y de investigación" (p. 501). Sin embargo, pese a eso el caso privilegiado sigue siendo el de México, al que le dedica el 80 por ciento del capítulo. Este es un análisis desigual, en el que habla de todo un poco sin que exista un eje medular. Habla de la independencia, del sindicalismo de Estado, de los factores étnicos, pero finalmente no queda nada en claro. Como se ocupa principalmente de México, es como si no hubieran existido luchas sociales de verdadera importancia en los otros países del continente. Seguidamente se analiza la cuestión de las cris is políticas y de las revueltas elitistas, el impacto de las grandes cris is mundiales particulamente la de 1929; las sublevaciones campesinas y las insurrecciones populares. En el anális is de es os movimientos se tiene en cuenta la importancia de los problemas agrarios y el peso de las comunidades indias. El estudio del movimiento obrero y sindical solamente es tratado con respecto al sindicalismo de Estado. Empero, no hay un estudio profundo sobre su importancia histórica en ciertos países (Brasil, Argentina, y el mismo México) y se descuidan igualmente los grandes momentos de la historia obrera durante los primeros decenios del siglo XX.

Una segunda parte de ese capitulo pretende estudiar las revoluciones en América Latina desde el siglo XIX. Como ya es habitual, el caso mexicano ocupa la parte substancial del capitulo (p. 543-580). De la misma manera, se analiza la "revolución boliviana" de 1952 y el desarrollo de ese país hasta el día de hoy (pp 580-584). El capitulo temina con algunas notas sobre la revolución cubana (584587). Lo que resulta chocante en este capítulo es que se le consagren 36 paginas a la Revolución Mexicana mientras que se aborde en menos de tres páginas a la Revolución Cubana, un evento histórico de consecuencias mundiales en la his toria contemporánea. Es mas que legitimo demandarse porque tal desproporción entre esos dos eventos, si se tiene en cuenta su desigual influencia en la historia contemporánea del continente, en la que indiscutiblemente la Revolución Cubana ha sido el suceso más importante del último medio siglo ¿por qué se da mas importancia a la revolución mexicana e incluso a la "Revolución boliviana" que a la cubana?

Una cosa es que no se esté de acuerdo con la Revolución cubana -que explícitamente es la posición de Chevalier y su colaborador, quienes no simpatizan para nada con este proceso- pero una bien distinta es desconocer e ignorarla como lo hacen. Por algo no presentan un relato histórico sobre las fases de la revolución cubana sino que se limitan a despacharla en forma lapidaria. Sin analizar para nada el proceso, afirman en el primer párrafo consagrado al tema, que "de repente, Cuba y el régimen de Castro se han convertido, al tiempo del hundimiento de la Unión Soviética, en vestigios dictatoriales de una época anticuada" (p. 585). En épocas de dominio neoliberal y de discurso histórico neoconservador, todo lo que no este de acuerdo al orden en curso, aparece como anticuado. Para Chevalier y su colaborador, el gobierno cubano es más represivo que los otros del continente (lbid). Con este tipo de afimaciones sueltas, no demostradas en el texto, ahora si entiende el por qué de las referencias 
apologéticas a las dictaduras militares del continente y a gobiernos neoliberales como el de Salinas

Sobre los otros procesos, como la revolución sandinista o la lucha en el Salvador no hay ni una sola mención, como si no hubieran existido. Así, se está incurriendo en una doble negación: primero la de sus opositores reales, encabezados por Estados Unidos, que las liquidaron físicamente y ahora la de los historiadores franceses que ni siquiera le dedican un renglón. Hasta ese extremo nos conduce la visión neoconservadora de la historia, a la negación y desconocimiento de sucesos históricos que han jalonado, para mal o para bien esa sería otra dis cusión, la historia presente del continente latinoamericano.

En el último capítulo se estudian las caracterís ticas de los sistemas políticos. El punto de partida es la manera particular como, a comienzos del siglo XIX, se configuraron los nacientes estados republicanos, los cuales se inspiran particularmente en Inglaterra, Francia y Estados Unidos. Se subraya el rol jugada por los caudillos en la formación de los nuevos estados. Enseguida se analiza diferentes ejemplos nacionales. El caso mejicano ocupa de nuevo un lugar preferencial (pp. 599-618). Después se consideran otros ejemplos, tales como el de Haití durante la revolución de independencia, el de Colombia has ta el momento actual, el de Venezuela después de 1958, el de los piases indoandinos sobretodo durante el siglo XIX. Hay otros casos, como el de Chile y el de Brasil. En este capitulo hay una descripción de casos particulares y falta un esfuerzo por hacer un anális is general comparativo. Por lo demás, a partir de la información de cada ejemplo no es posible que el lector haga la comparación, pues la información es muy heterogénea. En efecto, para algunos países el anális is llega hasta hoy y en otros se hace solamente un relato de eventos del siglo pasado.

\section{CONCLUSIÓN}

Para concluir, como creemos haberlo demostrado a lo largo de este ensayo, podemos decir que este libro es una muy pésima contribución a la historiografía latinoamericana y un modelo de cómo no se debe es cribir una historia de síntesis. Sus autores habrían podido mirar -sólo mirar- algunos de los magistrales libros de síntesis de Eric Hobsbawm para aprender un poquito al respecto. El libro de Chevalier no es, precisamente, el modelo ideal para escribir síntesis histórica porque en cada capítulo hay disgreciones innecesarias y exceso de erudición. Se mencionan con detalle las fuentes, los métodos, los autores y se evocan con exceso de prolijidad los problemas propios de la investigación histórica que solo interesan a los historiadores profesionales. Un libro de síntesis no debe ser el lugar para hacer todo esto a la vez. En verdad el título de este libro debería ser "Una historia comparativa de México en el siglo XIX, con algunas glosas del siglo XX", puesto que este siglo está prácticamente ausente o es bien marginal y la historia de América Latina se reduce al caso de México, al parecer porque a la historia de ese país se han dedicado tanto Chevalier como sus discípulos. El discurso no es ameno y aparecen saltos inexplicables de un tema a otro. 
El libro se concentra principalmente en la historia del siglo XIX y no en los fenómenos posteriores a 1930. En el libro, la historia contemporánea del continente se encuentra subordinada a las consideraciones del proceso postindependentista. Por esta razón, la inexistencia de un estudio sistemático de los principales problemas históricos de los últimos 50 años, tales como la Revolución Cubana, las dictaduras militares y la crisis políticas. Naturalmente, todos estos eventos son considerados en el libro, pero de una forma totalmente marginal, sin medir su verdadero significado his tórico en la vida continental.

Por último, hay que decir que en el continente americano existen dos regiones claramente diferentes: la América anglosajona y la América Latina. El libro comentado pretende ser una historia de esta última región. Ahora bien, el análisis es hecho de una manera completamente aislada como si después de la independencia las potencias mundiales (primero Inglaterra y Francia y después los Estados Unidos) no hubieran jugado un rol importante en la historia latinoamericana. ¿Se puede comprender esta historia durante un siglo y medio como si la acción, por ejemplo, de los Estados Unidos no hubiera afectado de ninguna manera a la región?

Respecto a esta compleja cuestión se puede caer en dos posiciones extremas: 1. La de decir que todos los sucesos históricos al sur del Río Bravo son el producto de la acción del imperialismo yanqui, que es la posición que abiertamente critica Chevalier 2. La de ignorar completamente el papel de Estados Unidos en la América Latina, hasta el punto de desconocer hechos tan palpables como las ocupaciones territoriales de Nicaragua, Haití, República Dominica, Cuba, Puerto Rico, el robo de Panamá, etc., y de explicar la historia continental como si el imperio americano nunca hubiera existido. En esta segunda posición de una historia totalmente aislada y soberana, se ubica el libro de F. Chevalier. Con respecto a esta cuestión, es chocante que en todo el libro no exista ni una sola mención a las invasiones territoriales de Estados Unidos a México, objeto privilegiado del libro y tema de sobra conocido por su autor y no se nombre una sola acción de agresión de Estados Unidos en la región. De la misma forma, no hay ninguna consideración sobre la política de Estados Unidos hacia Latinoamérica durante todo el siglo XX, que lo condujo a patrocinar las dictaduras militares más divers as: Duvalier en Haití, Som oza en Nicaragua, Batista en Cuba, Juan Vicente Gómez en Venezuela, Pinochet en Chile, Videla en Argentina. Olvidando esta política intemacional de Estados Unidos no se puede comprender la historia de América Latina, aunque des de luego nuestra his toria no se reduzca a ese solo hecho.

El autor debería haber aplicado sus preocupaciones geopolíticas que tanto lo embargan cuando se refiere a la historiografía marxista, a un tema mucho más pertinente al respecto, como es el relacionado con los intereses de Estados Unidos en el continente. Pero ahí si se olvidaron de la geopolítica, para proporcionar una imagen absolutamente unilateral de la historia de la América Latina. Al parecer, según los doctores de París, en esta parte del mundo nunca ha vivido una sola intervención militar ni de Estados ni de otras potencias; ni éstas 
han patrocinado un solo golpe de Estado; jamas han impulsado políticas contrainsurgentes ni anticomunistas; y mucho menos han perseguido y liquidado la democracia a lo largo y ancho de la región. Una historia de América Latina que no considere esos factores no es nuestra historia. Es difícil reconocerse en una exposición de esta naturaleza en la que la vida continental sólo ha sido regida por intereses puramente intemos, como si las potencias no hubieran existido y nunca hubieran intervenido en la vida continental. En el libro de Chevalier la historia del continente desde la independencia es un relato idílico de hechos aislados, que no han tenido ninguna relación con el resto del mundo, ni con el imperialismo ni con el capitalismo. Hasta allá conduce tranquilamente la pretensión de la Nouvelle Histoire française de despolitizar la his toria, cosa que solo es una pretensión pues aquí la politización a la inversa es total y se encuentra presente a lo largo de todo el análisis; esa politización temina siendo una apología vulgar de la acción de Estados Unidos y de los gobiernos neoliberales del continente latinoamericano y expresa una abierta oposición y rechazo a todas las causas populares. 